\title{
A New Hybrid Dynamic FMECA with Decision-Making Meth- odology: A Case Study in An Agri-Food Company
}

\author{
Mario Di Nardo *, Teresa Murino, Gianluca Osteria and Liberatina Carmela Santillo
}

\begin{abstract}
Department of Chemical, Materials and Industrial Production Engineering (DICMAPI), University of Naples Federico II, Naples, Italymurino@unina.it (TM); gianluca.osteria@gmail.com (GO); santillo@unina.it (LCS.)

* Correspondence: . mario.dinardo@unina.it
\end{abstract}

\begin{abstract}
The Failure Mode and Effect Analysis (FMEA) is often used to improve a system's reliability. This paper proposes a new approach that aims to overcome the most critical defects of the traditional FMEA. This new methodology combines the Entropy and Best Worst Method (BWM) methodology with the EDas and System Dynamics, FMECA: The EN-B-ED Dynamic FMECA. The main innovation's point of the proposed work is the presence of an unknown factor (Cost), that allows to obtain an objective weighted factor, a risk index when a machine failure occurs. The criticality analysis has been carried out using software (Vensim PLE x64) to simulate System Dynamics models to identify corrective actions and evaluating the possible implementation of these actions. The methodology proposed is applied to a case study in a relevant Italian company in the agri-food sector.
\end{abstract}

Keywords: FMEA; FMECA; MCDM; Entropy method; BWM; EDas method; System Dynamics

\section{Introduction}

Reliability is defined as the probability that a component or a system will perform its intended functions over a specified period under stated operating conditions (Ebeling, 2019). The reliability of a system is essential for a successful business and this study proposes a straightforward and replicable analysis to increase the reliability of a system.

In recent decades, organisations and research companies have developed methods to mitigate or eliminate sudden events that would reduce the system's reliability. Engineers, to ensure system safety and reliability, identify all possible failures during the life cycle of a system and prepare actions to reduce failures or mitigate their consequences. At this regard, FMEA (Failure Mode and Effect Analysis) is a structured method to identify failure modes and their consequences. (Kim \& Zuo, 2018). It becomes quantitative adding critically analysis called FMECA (Failure Mode Effects and Critically Analysis)(Cristea \& Constantinescu, 2017).

Through these methods, three factors, the fault Occurrence (O) , the Severity (S) and the Detectability (D), are evaluated, generally using a scale of 10 values. Then the FMECA provides, after calculating the RPN, obtained by multiplying the value assigned to each factor, the ranking of causes to identify the most critical failure causes. On these causes, the corrective actions to be implemented and evaluated must be sought. Although the FMEA is a widespread analysis, its shortcomings are many and, in the literature such as Braglia, Carmigiani etc. , we will provide a deeper analysis in the next section.

The most cited shortcomings concern the absence of weights on $\mathrm{O}, \mathrm{S}$ and $\mathrm{D}$ factors, the absence of economic factors, the absence of scientific basis in the RPN calculation formula, and many duplicates in RPN results.

In the following work, we propose an innovative method called "EN-B-ED Dynamic FMECA", to solve some of the main shortcomings of the traditional FMEA. A factor related to the cost arising from the occurrence of the failure has been added and two multi- 
criteria methodologies, the Entropy method and the BWM, have been used in combination to calculate the weights of the criteria. Also, the alternatives have been ranked using the EDas method, much more academically supported than the classic RPN.

Finally, the last step of our innovative methodology, was the development of a criticality analysis with the use of system dynamics to give dynamism to the model and evaluate the system as a complex set of elements and not as is done in the traditional FMEA as a set of distinct and separate components.

A case study carried out on a machine of an important Italian company in the agrifood sector is presented to evaluate the proposed mode's robustness.

The paper is organised as follows. In section 2 a brief report on the state of the art of the FMECA is proposed with particular attention to the developments proposed in conjunction with MCDM. In Section 3, the problem is defined generically, and the methodology is proposed. Section 4 describes the case study. Finally, the last chapter, Section 5, focuses on conclusions and proposals for future work developments.

\section{Literature review}

Scopus is the database used to search related literature. We searched "FMEA" or "FMECA", and extracted a total of 3649 papers. Before highlighting the critical issues found, let's try to understand how an FMEA analysis is performed.

A complete FMEA analysis consists of 4 steps (Stamatis, 2003) :

1. Identify all failure modes that have occurred or potential failure of a system.

2. Identify the causes and effects of faults.

3. Ranking the identified failure modes through RPN (Risk Priority Number)

4. Take corrective action.

In the third step, the RPN makes the FMEA a quantitative method.

In order to carry out a correct FMEA analysis and identify all possible failure modes, a diversified team of people with different backgrounds (e.g., mechanical design, software, production, maintenance) is usually involved in doing this, as this increases the probability that all failures will be identified and the effects correctly estimated (Cristea \& Constantinescu, 2017).

The RPN index is the product of three factors (Ciani et al., 2019):

- Occurrence $(\mathrm{O})$ is the probability that a failure mode will occur. It is, therefore, strongly linked to the failure rate of the component.

- $\quad$ Severity $(S)$ is related to the effect/impact of the fault model.

- Detectability (D) indicates the ability to diagnose the fault mode before its effects occur on the system.

$$
R P N=O \times S \times D
$$

The conventional method of RPN calculation has been widely analysed in literature for several reasons.

\subsection{State of the art and research problem}

The FMEA is an analysis led by a team to identify the possible failure mode in a system, the causes and effects associated with them, which may occur. When unacceptable failure effects verify, design changes must be done to either eliminate or reduce the failure causes. The first uses of FMEA as a structured methodology can be found in the United States Department of Defense and applied by the National Air Force and Space Administration (NASA) for the Apollo plan to improve the reliability of the system in the 1960s.Thanks to its ease of use, FMEA has been successfully applied in various sectors such as aerospace, automotive, etc.( J. Bowles e C. Peláez, 2003). The main weaknesses of the methodology 
concern the subjectivity inherent in the attribution of values to the three indexes of $\mathrm{S}, \mathrm{O}$, $\mathrm{D}$, which have the same weight on the criticality of the single type of fault, and the lack of decision support taking into account of components costs.. In order to overcome the criticality of the single failure, the criticality analysis, that turns FMEA into FMECA, is introduced to prioritise failures based on the likelihood of the item failure mode and the severity of its impacts. To calculate each factor $\mathrm{O}, \mathrm{S}$, and D, some researchers give them the same importance Chin et al. 2009) (Carmignani G., 2009) (Liu et al., 2011). However, the change of the value of these can produce the same RPN value even if they hide a different risk (Chin et al. 2009) (Chin \& Yang, 2009). Understanding the information in an FMEA/FMECA analysis is insufficient to assess the three factors with certainly and directness (Xu et al., 2002). It is due to a no scientific basis of the mathematical formulation of the RPN, which ignores the importance of corrective actions and is calculated only from a risk point of view (Pillay \& Wang, 2003) (Carmignani G., 2009). Furthermore, the mathematical form adopted by RPN is susceptible to variations in the valuation of individual factors. Same RPN values can be generated from different O, S, and D values up to 24 combinations for the same RPN (Seyed-Hosseini et al. 2006). According to the papers cited, it is clear that the interdependencies among the various error modes and the effects are not considered and the RPN takes into account only three safety-oriented factors, not weighted and ranked, altogether leaving out economic factors. Therefore, the FMEA/FMECA has been combined with many techniques to reduce/eliminate the observed weaknesses to overcome these shortcomings. The methods used in literature are divided into five main categories, which are Multi-Criteria Decision Making (MCDM), Mathematical Programming (MP), Artificial Intelligence (AI), hybrid approaches, and others (Liu et al., 2013). MCDM techniques are the most frequently used category. FMEA/FMECA analysis can be seen as an MCDM problem due to multiple risk factors in assessing and prioritising failure modes. In this regard in literature, several methods are combined with FMEA/FMECA. Braglia developed a multi-attribute analysis called MultiAttribute Failure Modes Analysis (MAFMA) using the Analytic Hierarchic Process (AHP) to solve the shortcomings of the traditional FMEA related to the RPN. The expected cost of the intervention is also considered (Braglia, 2020). Other studies combine the FMECA analysis method with the Technique for Order Preference by Similarity to Ideal Solution (TOPSIS) (Braglia et al., 2003) to overcome some limitations of the conventional FMECA proposing a new way to calculate the RPN based on the TOPSIS method with Fuzzy Logic. The uses of the TOPSIS method in real cases are not few, it can be applied applied in a food sector company to reduce and stabilise maintenance costs (Selim, Yunusoglu, \& Yilmaz Balaman, 2016). In 2017 it was used to monitor possible failure of a submarine control module (Kolios et al., 2017). The combining use of Preference Organization Ranking Model PROMETHEE] and FMEA, proposed by (Lolli, Ishizaka, Gamberini, Rimini, \& Messori, 2015) wants to establish a multi-criterion group decision support system based to classify failure modes into priority classes in the FMEA. In addition to PROMETHEE, the Group Decision Support Systems (GDSS) for the sorting of faults. The study proposed by (Liu H.-C. et al., 2012) combines the FMEA and the VIseKriterijumska Optimizacija Kompromisno Resenje (VIKOR) method to rank the indices and then classify the failure modes. The literature analysis clearly shows that the RPN calculation is critical, and some different approaches have been proposed to overcome this limit. The BWM has often been used in conjunction with other methods, such as with VIKOR (Tian, Wang, \& Zhang, 2018) or with grey theory (Lo H.-W. L., December 2018). The Decision Making Trial and Evaluation Laboratory (DAMATEL) method wants to determine the risk priority of failure modes based on the severity of the effect and the direct and indirect relationships (SeyedHosseini et al. 2006). The lack of mathematical rigour in the formulation of the RPN and its subjectivity in calculating the three parameters $\mathrm{O}, \mathrm{S}$ and $\mathrm{D}$, is studied with the Fusion FMEA method based on 2-tuple linguistic information and interval probability to analyse the failure modes taking into account heterogeneous information rather than single type information. (Ouyang et. Al 2021). 
In general, the authors presented focused on three main limits of the traditional FMEA/FMECA that are :

- first is how the RPN index is calculated; many researchers have focused on determining a replicable method to identify different weights to be assigned to various criteria;

- $\quad$ secondly, many scholars have focused on finding a method that would allow the proper evaluation of alternatives in the case of linguistic variables and, therefore, in cases of uncertainty;

- $\quad$ finally, in recent years, the academic world has tried to solve another critical shortcoming of the traditional FMEA, the lack of some factors, first of all, the cost. Therefore, many methods involve the use of several factors.

In this research paper, it is presented a new methodology to overcome FMEA's shortcomings, such as:

- the absence of weights on $\mathrm{O}, \mathrm{S}$, and D factors.

- the lack of economic factors.

- the absence of scientific basis in the RPN calculation formula, and many duplicates in $\mathrm{RPN}$ results.

\section{Problem definition}

The EN-B-ED Dynamic FMECA can be used to prevent a failure in a process or machinery. In this study is presented an EN-B-ED Dynamic FMECA on machinery. When the machinery is broken down into its functional units, its main components are identified. The various failure modes must be identified for each component, and for each failure mode, the possible causes must be analysed. The factors for each cause of failure are evaluated.

The proposed methodology can be used to rank the causes and see what the critical events are. In Table 1 the starting table of our method is presented:

Table 1. Problem formulation.

\begin{tabular}{ccccccccc}
\hline $\begin{array}{c}\text { Functional } \\
\text { area }\end{array}$ & Components & $\begin{array}{c}\text { Failure } \\
\text { mode }\end{array}$ & $\begin{array}{c}\text { Failure } \\
\text { cause }\end{array}$ & Effect & Occurrence & Severity & Detectability & Cost \\
\hline$U_{i}$ & $C_{j}$ & $F M_{k}$ & $C F_{l}$ & $E_{m}$ & $X$ & $X$ & $X$ \\
\hline
\end{tabular}

In Table 2, a list of the nomenclature used in this methodology is presented.

Table 2. Nomenclature table.

\begin{tabular}{cc}
\hline $\mathrm{S}$ & Severity \\
\hline $\mathrm{O}$ & Occurrence \\
\hline $\mathrm{D}$ & Detectability \\
\hline $\mathrm{C}$ & Cost \\
\hline $\mathrm{I}$ & Index referring to the alternatives \\
\hline $\mathrm{J}$ & Index referring to the criteria \\
\hline$x_{i j}$ & Element of initial Decision matrix \\
\hline$z_{i j}$ & Element of Entropy normalisation-matrix \\
\hline $\mathrm{N}$ & Criteria's number \\
\hline $\mathrm{M}$ & Cost of non-production \\
\hline$C_{M P}$ & Cost of production manpower \\
\hline$C_{h p}$ & The extraordinary cost of production man- \\
\hline$C_{h p s}$ & power
\end{tabular}




\begin{tabular}{cc}
\hline$C_{M D O}$ & Cost of maintenance manpower \\
\hline$C_{R}$ & Cost of spare parts \\
\hline$E_{j}$ & Entropy of j-th criteria \\
\hline$d_{j}$ & Degrees of variation \\
\hline$W_{j(E)}$ & Weight of the j-th criteria by entropy method \\
\hline$W_{j(B W M)}$ & Weight of the j-th criteria by Best Worst \\
& Method \\
\hline$A V_{j}$ & Average value of Decision Matrix \\
\hline PDA & Positive distance to average \\
\hline NDA & Negative distance to average \\
\hline SP & Weighted sum of PDA for each alternative \\
\hline SN & Weighted sum of NDA for each alternative \\
\hline NSP & Normalised SP \\
\hline NSN & Normalise SN \\
\hline AS & Appraisal score \\
\hline
\end{tabular}

\subsection{Proposed methodology}

Each step of this proposed method will be explained in detail in this section. Figure 1 , represents the flow chart of the logical sequence of operations to correctly execute the EN-B-ED Dynamic FMECA.

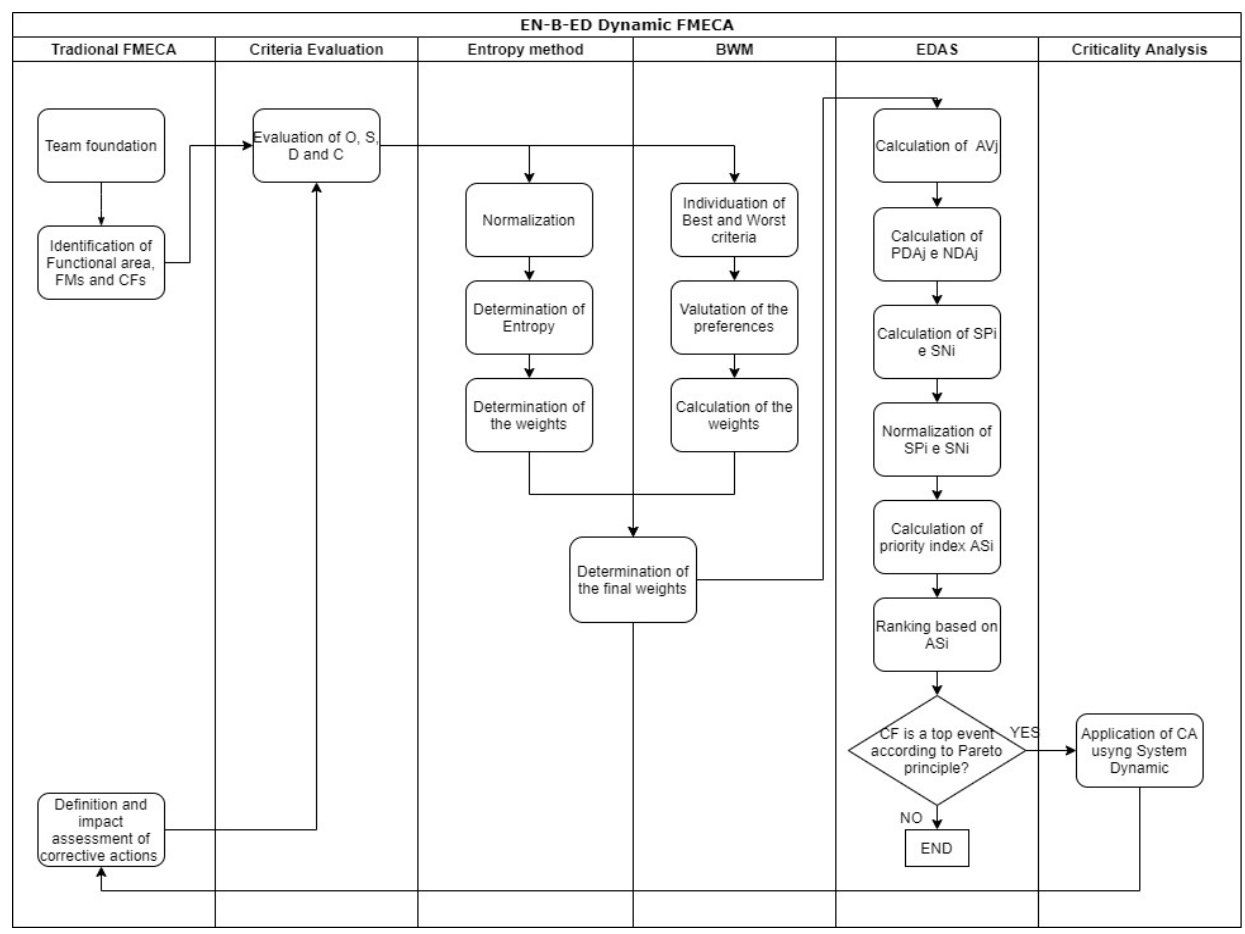

Figure 1. Flow chart of the proposed methodology.

3.1.1. Multidisciplinary team creation, machine breakdown into functional units and identification of FMs and CFS

The proposed methodology starts from a classical FMEA analysis with a multidisciplinary team of specialists who identify the critical areas of the system analysing them. The output of this analysis is the identification of the possible failures modes and the related causes and effects. Hence, the criteria that best describe the risk associated with FMs are defined and the criterion for each possible cause of the fault is evaluated. 


\subsubsection{Evaluation of the factors $O, S, D$, and $C$}

The first innovation point of EN-B-ED Dynamic FMECA analysis concerns the criteria used. We added the $\operatorname{cost} C$, in addition to the three traditional FMEA criteria, $O, S$ and $\mathrm{D}$, to consider the costs arising from the fault occurrence. This term considers:

- Costs of non-production $C_{M P}=\left(C_{h p} x N_{p} x T_{i}\right)+\left(Q_{p} x P_{p} x T_{i}\right)+\left(C_{h p s} x N_{p} x T_{i}\right)$ where $C_{h p}$ is the hourly cost of the production labor, $N_{p}$ is the number of workers, $T_{i}$ is the time of the maintenance intervention to restart the machine, $Q_{p}$ is the average quantity produced per hour, $P_{p}$ is the average price of the finished product, $C_{h p s}$ is the hourly overtime cost of the production labor. So, the first term takes into account the cost of the production unable to work during downtime, the second term takes into account the hidden costs resulting from the lack of production, and the last term instead takes into account the cost to be incurred if it is decided to pay overtime to recover lost production.

- $\quad$ Labour costs $C_{M D O}=\left(C_{h m} x N_{m} x T_{i}\right)$ (3) where $C_{h m}$ is the hourly cost of maintenance workers, $N_{m}$ is the number of maintenance workers and $T_{i}$ is the maintenance intervention time.

- $\quad$ Costs of spare parts used $C_{R}=\sum_{i=1}^{n} C_{i} Q_{i}$ (4) where $C_{i}$ is the cost of the i-th spare part and $Q_{i}$ is the number of spare parts i used

$$
C=C_{M P}+C_{M D O}+C_{R}
$$

\subsubsection{Criteria's weights calculation through Entropy method and Best Worst Method (BWM)}

Once obtained the starting matrix in which the possible alternatives are on the rows, the criteria on the columns, and the evaluations constitute the heart of the matrix, each criterion's weight must be identified.

In the traditional FMEA, a severe weakness, much discussed over the years, is the lack of different weights for the criteria; one factor may be predominant compared to the others.

This problem has been solved using a combination of the Entropy method and BWM to obtain the weights. This choice was made to not use methods that use language variables because these are difficult to manage and require very good experience to be used at best. There is a risk of incorrectly considering some subjective values as it is related to individual skills (Wang et al., 2013).

Although experts' subjective opinion is intrinsically present in the data structure, the combination with BWM has been made to take more account of business ideas (Lo \& Liou, 2018). Moreover, using the two methods makes the method replicable in any company, even where no objective maintenance data is available.

After calculating the weights with the two methods, a simple average or a weighted average of the values can be done; this depends mainly on how much the business ideas influence the maintenance aspects.

The Entropy method, according to (Trinkūnienè et al. 2017), will be applied as follows:

- The data of the matrix will be normalised to ensure a homogeneous and direct comparison between the criteria:

$$
Z_{i j}=\frac{x_{i j}}{\sum_{i=1}^{n} x_{i j}}
$$

- $\quad$ Entropy is calculated for each criterion: 


$$
E_{j}=\left(-\frac{1}{\ln (n)}\right) * \sum_{i=1}^{n}\left(Z_{i j} * \ln z_{i j}\right)
$$

- $\quad$ The values $d_{j}$ are calculated:

$$
d_{j}=1-E_{j}
$$

- $\quad$ Finally, weights $w_{j}$ are calculated:

$$
w_{j(e)}=\frac{d_{j}}{\sum_{j=1}^{m} d_{j}}
$$

The greater the weight of criterion $j$, the more critical will be the criterion $j$. If the values of criterion $j$ are almost equal, then it will be assigned a small weight because the entropy method is an objective method based solely and exclusively on the data structure and is in no way influenced by managerial policies (Trinkūnienè, et al.,2017).

The BWM will be applied as follows:

- The most important criterion and the least important criterion will be identified

- Preferences of the most important criterion are expressed over the others by giving a number from 1 to 9 . You get a line vector

- Preferences of the least important criterion are expressed by giving a number from 1 to 9 . A column vector is obtained

- Finally, a problem of optimisation of the type is solved:

$$
\left\{\min \xi_{L}\right.
$$$$
\text { subjected to }
$$$$
\left|w_{B}-a_{B j} w_{j}\right| \leq \xi_{L}
$$$$
\left|w_{j}-a_{j w} w_{w}\right| \leq \xi_{L}
$$$$
\sum_{j=1}^{m} w_{j}=1
$$

$\left.w_{j} \geq 0\right\}$

to obtain the weights of the criteria.

\subsubsection{Calculation of final weights}

Once $w_{j(e)}$ e $w_{j(B W)}$ have been calculated, the final weights must be determined in the following way:

$$
w_{j}=E * w_{j(e)}+B W * w_{j(B W)}
$$

where $\mathrm{E}$ is the weight you want to give to data from maintenance and $\mathrm{BW}$ is the weight you want to give to subjective data from experts.

\subsubsection{Application of the EDas method to rank alternatives}

The EDas method (evaluation based on distance from the mean solution) is a relatively recent MCDM problem-solving technique. It derives from considerations made on 
two methods: TOPSIS and WSM (Weighted Sum Method). It calculates the $\mathrm{AV}_{\mathrm{j}}$ (mean value) for each $j$-th criterion and evaluates each alternative's distance from this value.

According to (Trinkūnienè, Podvezko, \& Zavadskas, 2017), 7 steps must be followed:

- Calculate the average solution for each criterion $A V_{j}$

$$
A V_{j}=\frac{\sum_{i=1}^{n} x_{i j}}{n}
$$

- $\quad$ Calculate the mean positive distance $P D A_{i j}$ for the benefit and disadvantage criteria:

- Benefit

$$
\operatorname{PDA}_{j}=\frac{\left(\max \left\{0, x_{i j}-A V_{j}\right\}\right)}{A V_{j}}
$$

- Disadvantage

$$
\operatorname{PDA}_{j}=\frac{\left(\max \left\{0, A V_{j}-x_{i j}\right\}\right)}{A V_{j}}
$$

- Calculate the mean negative distance $N D A_{i j}$ for the benefit and disadvantage criteria:

- Benefit

$$
\mathrm{NDA}_{\mathrm{j}}=\frac{\left(\max \left\{0, A V_{\mathrm{j}}-\mathrm{x}_{\mathrm{ij}}\right\}\right)}{A V_{\mathrm{j}}}
$$

- Disadvantage

$$
\mathrm{NDA}_{j}=\frac{\left(\max \left\{0, \mathrm{x}_{\mathrm{ij}}-A V_{\mathrm{j}}\right\}\right)}{A V_{j}}
$$

- Using the weights of the previously calculated criteria, the weighted sums are calculated, $S P_{i}$

$$
\mathrm{SP}_{\mathrm{i}}=\sum_{\mathrm{j}=1}^{\mathrm{m}} \mathrm{w}_{\mathrm{j}} * \mathrm{PDA}_{\mathrm{j}}
$$

- Using the weights of the previously calculated criteria, the weighted sums are calculated, $S N_{i}$

$$
\mathrm{SN}_{\mathrm{i}}=\sum_{\mathrm{j}=1}^{\mathrm{m}} \mathrm{w}_{\mathrm{j}} * \mathrm{NDA}_{\mathrm{j}}
$$

- $\quad$ The weighted sums are normalised

$$
\begin{gathered}
N S P_{i}=\frac{S P_{i}}{\max \left\{S P_{i}\right\}} \\
N S N_{i}=1-\frac{S N_{i}}{\max \left\{S N_{i}\right\}}
\end{gathered}
$$

- The priority index, $A S_{i}$, is calculated

$$
A S_{i}=\frac{1}{2}\left(N S P_{i}+N S N_{i}\right)
$$


The ranking of the possible causes of failure is evaluated following descending order of the AS index.

\subsubsection{Criticality Analysis (CA)}

The CA consists of a qualitative, quantitative, or semi-quantitative analysis used to identify the critical causes of a system failure or those where it is convenient to intervene most urgently. There are several methods to perform this analysis. One of these is to use the Hazard Score Matrix, in which only $S$ and $O$ are considered to assess the various risks of hazards (and incidents), and whose product is compared either with threshold values or through the Pareto principle analysis (Vala, Chemweno, Pintelon, \& Muchiri, 2018), according to which $20 \%$ of the causes of faults cause $80 \%$ of total faults.

The Pareto principle of $80-20$ is applied to the EDas method's ranking to identify the most important critical issues.

In traditional FMECA, once the causes of critical failures have been identified, they are analysed individually and in a static way, i.e., without seeing how they evolve. Furthermore, in doing so, the interdependencies between the different failure modes are not considered (Carmignani G., 2009) (Xu et al., 2002). This is a weakness strongly discussed by scholars, the lack of dynamism. In doing so, one never looks at the machine's totality and how its conditions change over time.

A criticality analysis with a System Dynamics model is carried out to overcome this problem.

System Dynamics is an approach to considering a system not as a set of single independent components but as a single complex system in which causal relationships feed over time. Usually, simulation software captures the system's relational aspects and studies its behaviour over time. The concept of time is essential because, in classic FMECA, the causes of failure are considered one at a time, without considering how one influences the other and how the sum of their contributions accumulates over time, increasing the system's criticality.

In order to use System Dynamics correctly, it is first necessary to understand and be able to adequately represent the system's behaviour, finding and highlighting how the elements are reciprocally connected.

Then the criticality analysis will be conducted in a dynamic way examine how the simultaneity of the various causes of failure and their interactions influence the total probability of failure.

\subsubsection{Definition and impact assessment of corrective actions}

Once the system's criticalities have been identified, technicians and experts must be brought together to identify the corrective actions to be taken to lower the risk associated with the system. In this case, thanks to the use of System Dynamics, the technicians do not look only at the critical component but look at the totality of the system, questioning the influence that the various components have on each other and thus identifying corrective actions capable of lowering the entire failure risk associated with the machine.

Once corrective actions are identified, they are implemented and evaluated. To do this, the cycle illustrated in Figure 1 is repeated.

This generates an infinite cycle aimed at continuously improving the system's efficiency.

\section{Case study}

Our case study focuses on assessing a machinery called TR-CS re-coupling in a manufacturing company in the agro-food sector. Figure 2 shows a top view of it. 


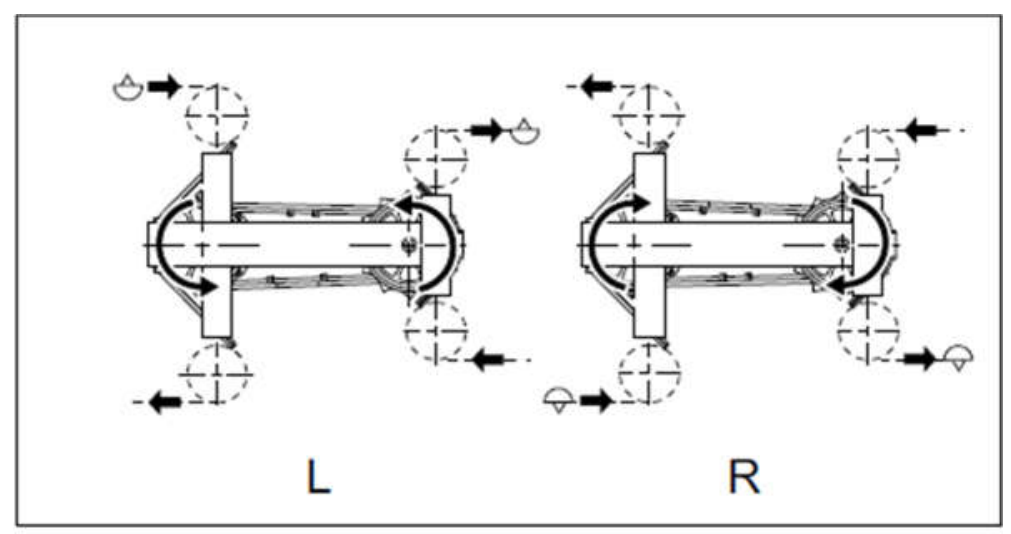

Figure 2. TR-CS top view.

This machine allows the transfer from-ene chain to another automatically. In Figure 3 the TR-CS coupling operation is shown.

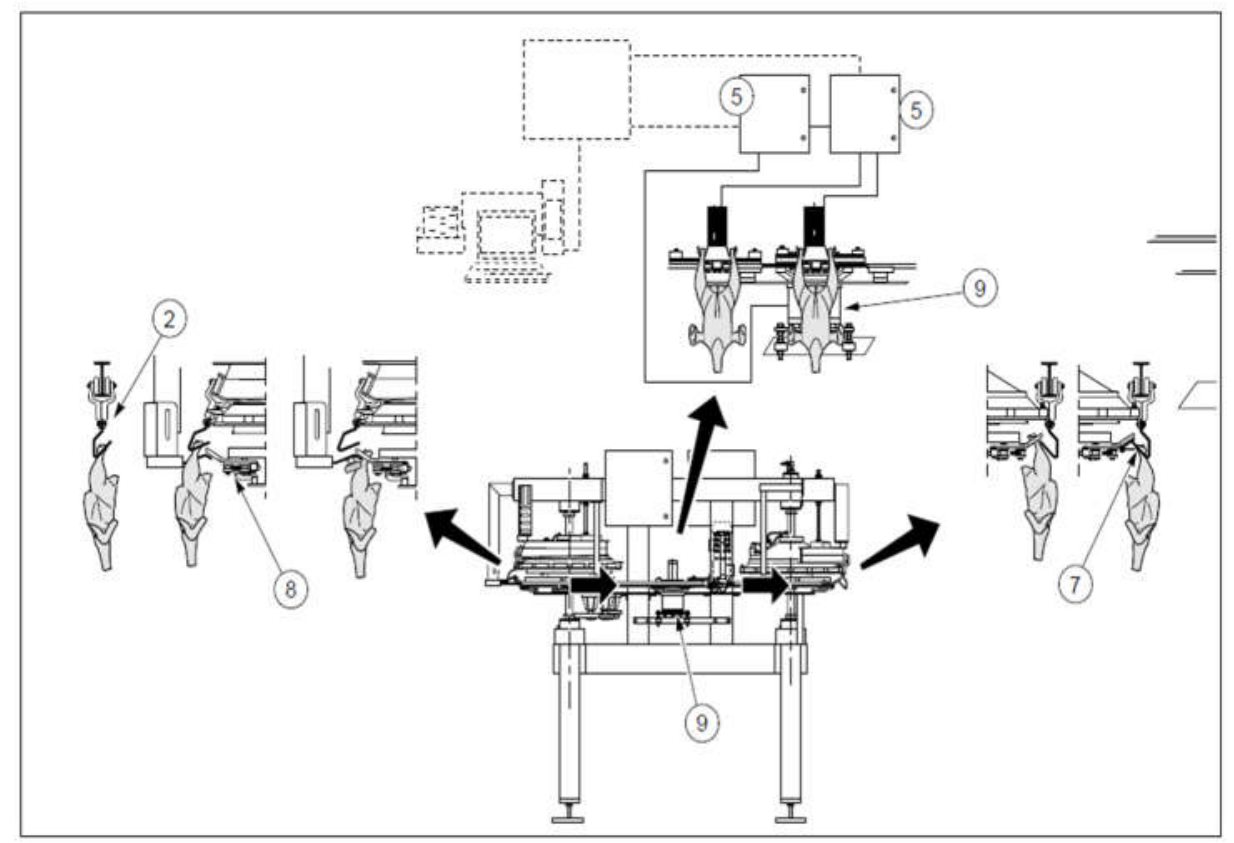

Figure 3. TR-CS process description.

The chickens arrive from the cooling tunnel, where they remain for at least 3 hours, hanging from the hook (in Figure 3 indicated with the number 2) of the cooling chain). The chicken is attached to the hook of the tunnel chain when it is still wet and then stops in the cooling tunnel where the temperature is lowered to better process the meat and allow it to dry. The chicken is welded more firmly to the hook, which is aligned with the front of the trolley of the transfer station (in Figure 3 indicated with the number 8), as it dries, making it more difficult to detach. If the hook is not aligned, the movement of the machine can damage or even break the chicken shanks. The transfer is enabled from the hook to the trolley by an extraordinary guide positioned to place the chicken. When the trolley exits 
the drive disc, it accelerates as the distance between the products increases, and it is driven to the weighing unit by a toothed belt (in Figure 3 with number 9). The product is weighed, and the relative data is provided to the control system during carriage on the side of the calibration line (in Figure 3 with number 5). The process is mirrored to the one just described on the right side, the side of the calibration line. The trolley is then aligned with the hook of the calibration chain (indicated by the number 7 in Figure 3), and a guide, suitably positioned, allows the chicken to be hooked to the calibration chain. Here the work of the guide is less onerous than that of the release guide because the chicken does not have time to "weld" to the carriage, and therefore it is easier to detach it.The process is equipped with a series of sensors that identify the hook " 0 " of the chains that allow to detect the presence of chickens, count them, weigh and match all the product data.

4.1.. Multidisciplinary team creation, machine breakdown into functional units, identification of FMs and CFs

The first step of our analysis is to form an interdisciplinary team. It is essential to bring together people with different technical backgrounds and several years of experience to identify all possible ways of system failure.

The team, during a couple of meetings, also thanks to the help of the machine manuals, has broken down the machine into six functional units:

1. Tunnel chain

2. Release chicken station (In Figure 4 indicated with a red box)

3. Transfer station (In Figure 4 indicated with a green box)

4. Hooking chickens' station (In Figure 4 indicated with an orange box)

5. Calibration chain

6. Electric circuit

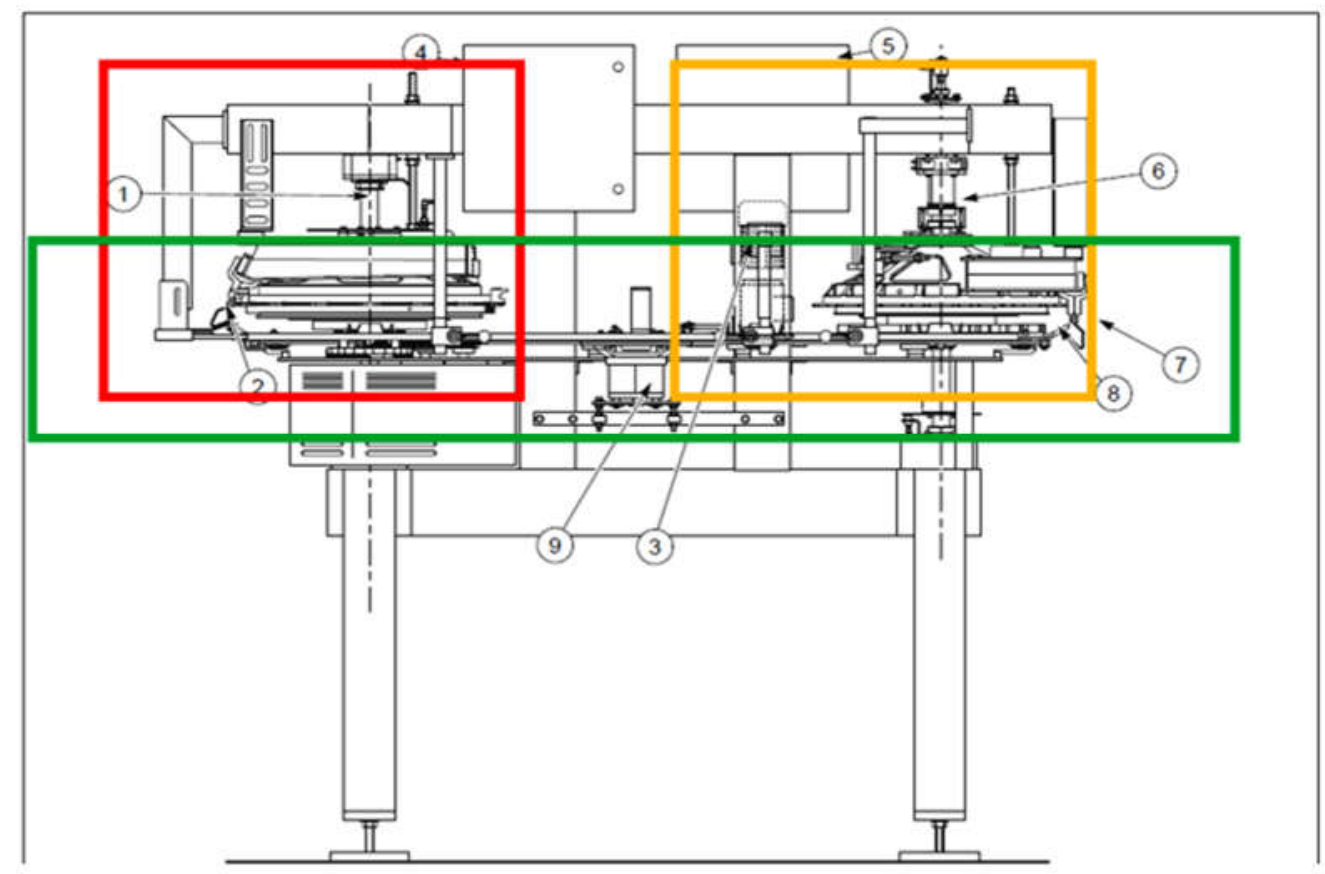


Figure 4. TR-CS functional unit.

Once the system was broken down into the various functional units, the functional units' main components were then identified. The possible failure modes have been identified for each component and the effects and causes of failure for each failure mode.

\subsection{Evaluation of the factors $O, S, D$, and $C$}

After this first work of breaking down the machinery and identifying faults and causes, the team focused on evaluating the four factors $\mathrm{O}, \mathrm{S}, \mathrm{D}$, and C. They followed their experience and a series of data from the maintenance management software.

In Appendix A - FMECA table, there is the starting matrix of the case study.

\subsection{Criteria's weights calculation through Entropy method and Best Worst Method (BWM)}

The next step of the proposed method involves applying the Entropy method to calculate the criteria' weights.

In Figure 5, a screenshot of the excel sheet is used. You can refer to Appendix B ENTROPY(supplementary material) for a complete analysis.
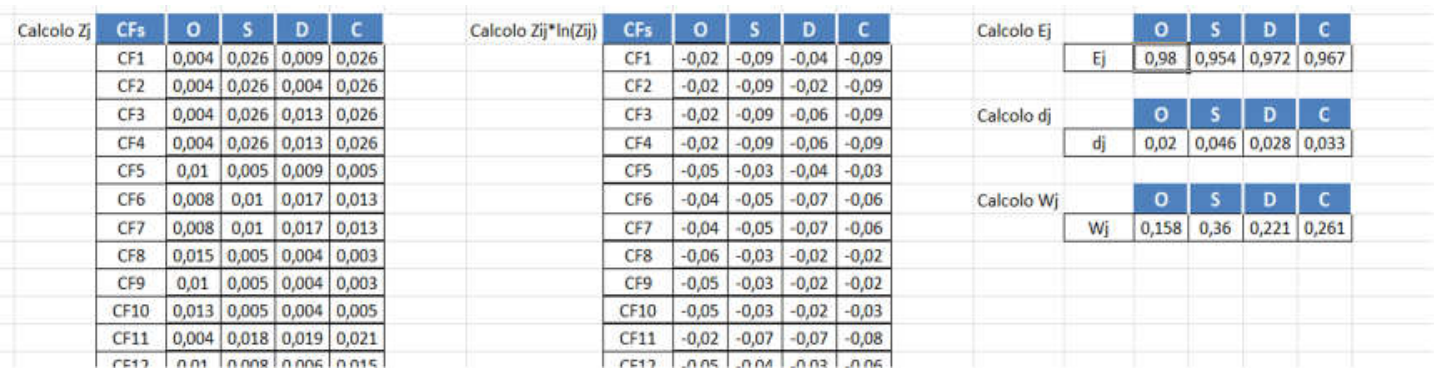

Figure 5. Excel worksheet extract by entropy method.

Once the criteria weights have been calculated with the Entropy method, you can calculate the weights with the BWM.

In Figure 5, there is a screenshot of the excel sheet used. For a complete analysis, you can refer to Appendix C - BWM.

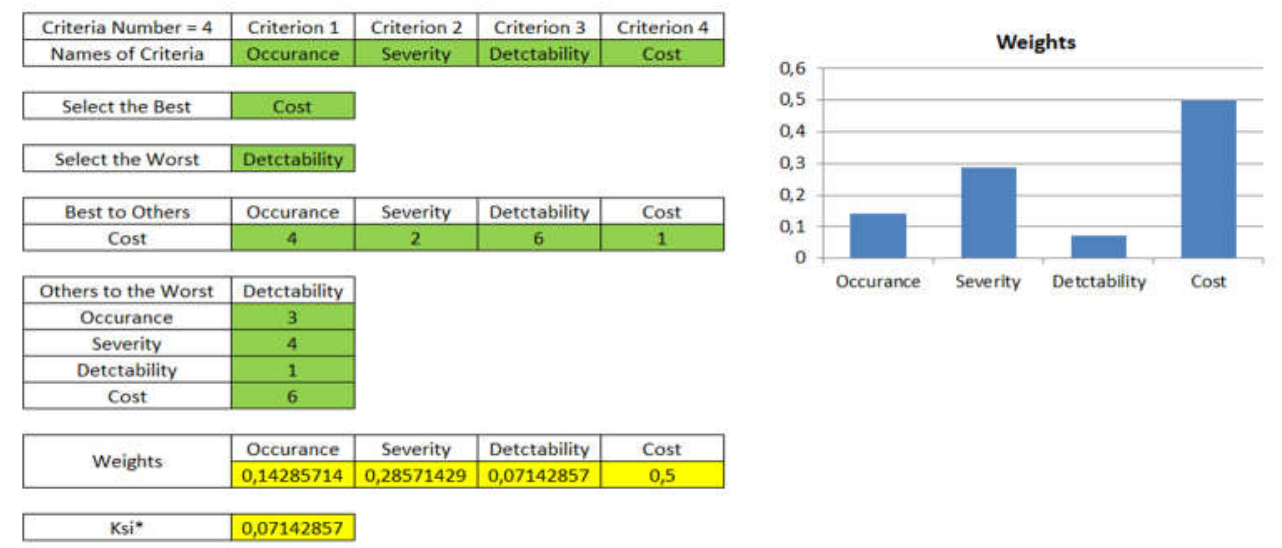

Figure 6. Extract Excel worksheet for BWM.

Once you have obtained the weights with the BWM, you can move on to the next step.

\subsection{Calculation of final weights}

Having the weights of the two criteria, all that remains is choosing their relative importance to proceed with the final calculation of the weights. 
In our case, according to the opinion of the team, it as decided to give the same weight to the two methods has been assigned :

$$
w_{j}=0.5 * w_{j(E)}+0.5 * w_{j(B W M)}
$$

Therefore, in our case study, the two methods have the same importance, so both the subjective data expressed a priori by the experts and the objective maintenance data were considered equally important.

Once the definitive weights of the criteria have been calculated, you can move on to the application phase of the EDas method to calculate the ranking of the alternatives.

\subsection{Application of the EDas method to rank alternatives}

Before reaching the criticality analysis, the last step of our methodology involves the use of the EDas method to calculate the ranking of alternatives.

Microsoft Excel was used to apply the EDas method, resulting in a worksheet full of information. For simplicity of representation, an extract of the fundamental part relating to the calculation of the Appraisal score and ranking is reported in Figure 7.

For a complete analysis, you can refer to the supplementary Appendix D - EDas.

\begin{tabular}{|c|c|c|c|c|c|c|c|c|c|c|}
\hline & CFs & SPi & SNi & NSPi & NSNi & ASi & & CFs & ASi & Rank \\
\hline \multirow[t]{27}{*}{ Calcolo ASi } & CF1 & 1,083324 & 0,099759 & 0,96263 & 0,813751 & 0,888191 & Calcolo il Rank & CF3 & 0,917766 & 1 \\
\hline & CF2 & 1,083324 & 0,180342 & 0,96263 & 0,663304 & 0,812967 & & CF4 & 0,917766 & 2 \\
\hline & CF3 & 1,125379 & 0,088093 & 1 & 0,835532 & 0,917766 & & CF1 & 0,888191 & 3 \\
\hline & CF4 & 1,125379 & 0,088093 & 1 & 0,835532 & 0,917766 & & CF72 & 0,831463 & 4 \\
\hline & CF5 & 0,005348 & 0,357916 & 0,004753 & 0,331776 & 0,168264 & & CF73 & 0,831463 & 5 \\
\hline & CF6 & 0,204045 & 0,025799 & 0,181312 & 0,951835 & 0,566574 & & CF2 & 0,812967 & 6 \\
\hline & CF7 & 0,204045 & 0,025799 & 0,181312 & 0,951835 & 0,566574 & & CF70 & 0,801887 & 7 \\
\hline & CF8 & 0,067642 & 0,535623 & 0,060106 & 0 & 0,030053 & & CF11 & 0,758539 & 8 \\
\hline & CF9 & 0,005348 & 0,535623 & 0,004753 & 0 & 0,002376 & & CF80 & 0,758539 & 9 \\
\hline & CF10 & 0,036495 & 0,438498 & 0,03243 & 0,181329 & 0,106879 & & CF71 & 0,726664 & 10 \\
\hline & CF11 & 0,766996 & 0,088093 & 0,681545 & 0,835532 & 0,758539 & & CF2O & 0,693634 & 11 \\
\hline & CF12 & 0,207445 & 0,143665 & 0,184334 & 0,731779 & 0,458056 & & CF21 & 0,693634 & 12 \\
\hline & CF13 & 0,067642 & 0,439488 & 0,060106 & 0,179482 & 0,119794 & & CF57 & 0,693634 & 13 \\
\hline & CF14 & 0,067642 & 0,439488 & 0,060106 & 0,179482 & 0,119794 & & CF58 & 0,693634 & 14 \\
\hline & CF15 & 0,109697 & 0,524945 & 0,097476 & 0,019934 & 0,058705 & & CF86 & 0,649812 & 15 \\
\hline & CF16 & 0,109697 & 0,524945 & 0,097476 & 0,019934 & 0,058705 & & CF91 & 0,649812 & 16 \\
\hline & CF17 & 0,288273 & 0 & 0,256156 & 1 & 0,628078 & & CF38 & 0,648558 & 17 \\
\hline & CF18 & 0,31942 & 0 & 0,283833 & 1 & 0,641917 & & CF18 & 0,641917 & 18 \\
\hline & CF19 & 0,31942 & 0 & 0,283833 & 1 & 0,641917 & & CF19 & 0,641917 & 19 \\
\hline & CF20 & 0,435822 & 0 & 0,387267 & 1 & 0,693634 & & CF55 & 0,641917 & 20 \\
\hline & CF21 & 0,435822 & 0 & 0,387267 & 1 & 0,693634 & & CF56 & 0,641917 & 21 \\
\hline & CF22 & 0,042055 & 0,41879 & 0,03737 & 0,218126 & 0,127748 & & CF17 & 0,628078 & 22 \\
\hline & CF23 & 0,095777 & 0,41879 & 0,085106 & 0,218126 & 0,151616 & & CF54 & 0,628078 & 23 \\
\hline & CF24 & 0,015194 & 0,45362 & 0,013501 & 0,153098 & 0,0833 & & CF93 & 0,609725 & 24 \\
\hline & CF25 & 0,102085 & 0,100943 & 0,090712 & 0,811542 & 0,451127 & & CF92 & 0,585857 & 25 \\
\hline & CF26 & 0,003296 & 0,207324 & 0,002929 & 0,612929 & 0,307929 & & CF6 & 0,566574 & 26 \\
\hline & rest & ก กกวว & ก 2ก7271 & ก กกวัว & ก 61ว0วo & ก 2ก70ว0 & & CET & ก БКБ5 7 A & 27 \\
\hline
\end{tabular}

Figure 7. Extract of excel worksheet for EDas method.

\subsection{Criticality analysis (CA)}

Our case study carried out the criticality analysis using Vensim PLE x64. A widely used software in System Dynamics models' simulation.

Before moving on to the construction of a CLD and then to the simulation, it is necessary to identify the critical events using the Pareto principle. This famous principle has often been used in criticality analysis (Lipol \& Haq, 2011).

The critical events found with the analysis carried out are those that the experts a priori indicated as critical events in the machine operation's deployment. Furthermore, in this study, the model proposed leads to actual results.

For ease of representation and analysis, it has been decided to exclude the causes CF55/CF57/CF58/CF70/CF71/CF72/CF73/CF80 from the analysis. The choice was taken into consideration since the causes are the same. Furthermore, all the actions and analyses 
that will be carried out on the causes related to the tunnel chain and the chicken release station can be proposed again strictly for the causes CF55/CF57/CF58/CF70/CF71/CF72/CF72/CF73/CF80 related to the calibration chain and the chicken release station.

Besides, the causes related to the chicken release station and the calibration chain are the most serious for the reasons mentioned above:

- The tunnel chain is considerably longer than the sizing chain; if it breaks, it causes more damage at the economic level.

- $\quad$ The release guide, on the other hand, unlike the hooking guide, is subject to more significant stress and, therefore, more prone to failure.

As already mentioned in this work, a dynamic simulation program is used to simultaneously study the causes of failure and not take them individually as in the traditional FMEA (Lipol \& Haq, 2011).

The first step is to represent the causal relationships between the variables present graphically. This diagram is called the Causal Loop Diagram (CLD). Thanks to CLD, it is possible to identify possible strengthening or balancing cycles (C., DR, B., \& WS, 2018).

These cycles are significant as they tell us if two or more failures increase each other over time or eliminate each other.

In Figure 8, an illustration of our Causal Loop Diagram is presented. To better understand the proposed CLD, a list is proposed that explains the representation:

- $\quad$ The causes of failure have been entered without a box;

- The failure modes have been entered in the circles;

- Effects have been placed in rectangles;

- Maintenance actions have been placed in hexes.

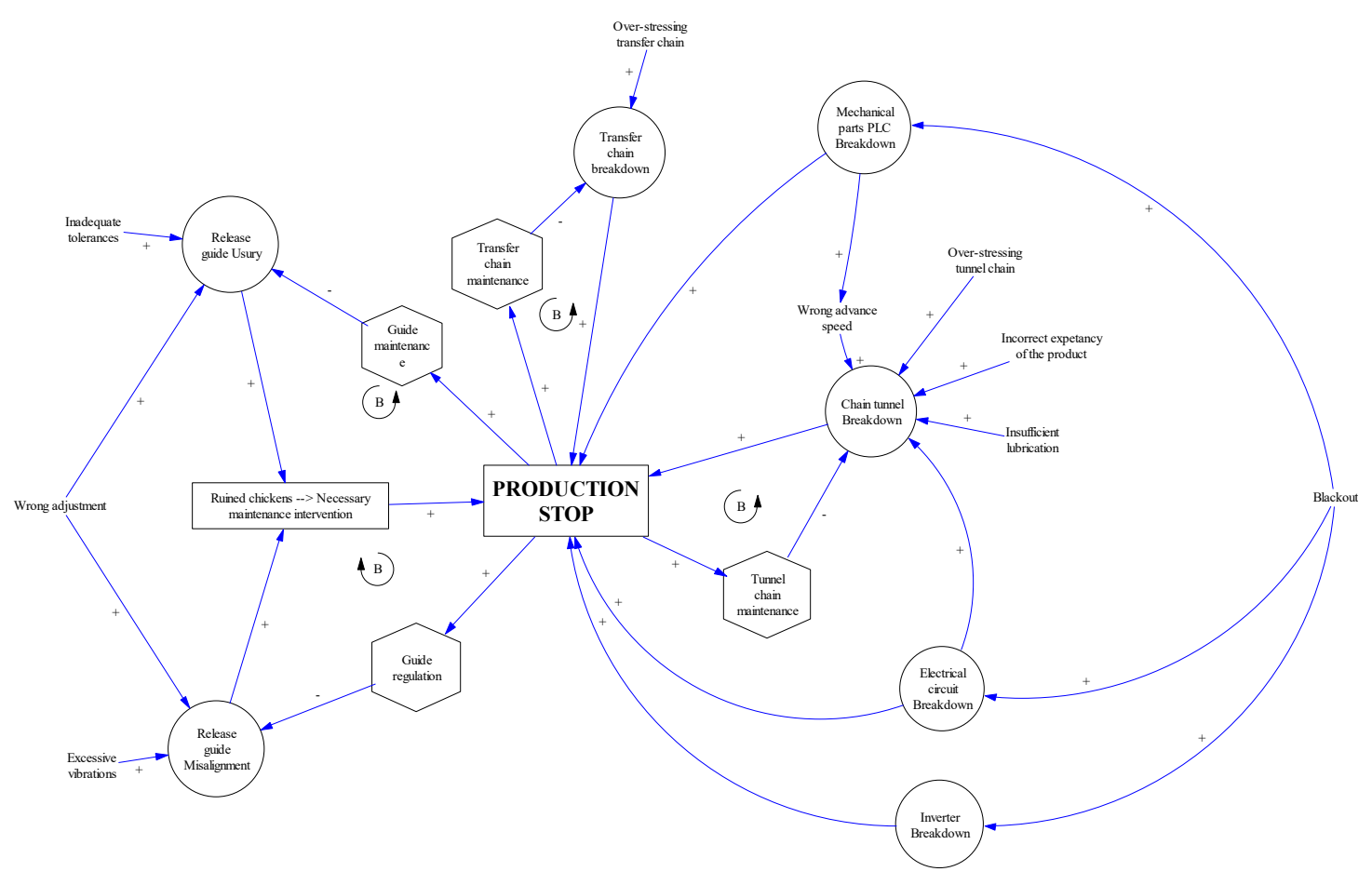

Figure 8. Causal Loop Diagram.

In the diagram, thanks to the presence of these maintenance interventions, four balancing loops can be seen:

1. FM10-E10-STOP PRODUCTION-Guide Maintenance-FM10

2. FM9-E10-STOP PRODUCTION-Guide Regulation-FM9 
3. FM1-STOP PRODUCTION-Tunnel chain maintenance-FM1

4. FM26-STOP PRODUCTION-Transfer chain maintenance-FM26

Since each cause has its stochastic properties, the probability distribution that best suits the different causes of failure must be identified:

- $\quad$ Due to the causes CF11 / CF86 / CF91 (Blackout), CF2 (incorrect feed speed), CF3 (Incorrect product life forecast), CF20 (Inadequate tolerances), being purely random events, the model that best interprets the behaviour is the exponential one.

$$
\begin{aligned}
F(t) & =1-\exp ^{-\lambda * t} \\
\mathrm{f}(\mathrm{t}) & =\lambda * \exp ^{-\lambda * t} \\
\mathrm{~h}(\mathrm{t}) & =\frac{f(t)}{1-F(t)}=\lambda
\end{aligned}
$$

Where $\lambda$ is the event occurrence frequency.

- $\quad$ For the causes CF18 / CF21 (Wrong adjustment), CF19 (Excessive vibrations), CF38 (Over-stressing), CF1 (Insufficient lubrication), CF4 (Over-stressing), being causes of failure of mechanical components, the model that best represents their behavior is Weibull's:

$$
\begin{gathered}
\mathrm{F}(\mathrm{t})=1-\exp ^{-\left(\frac{t}{\alpha}\right)^{\beta}} \\
\mathrm{f}(\mathrm{t})=\frac{\beta}{\alpha^{\beta}} * t^{\beta-1} * \exp ^{-\left(\frac{t}{\alpha}\right)^{\beta}} \\
\mathrm{h}(\mathrm{t})=\frac{f(t)}{1-F(t)}=\frac{\beta}{\alpha^{\beta}} * t^{\beta-1}
\end{gathered}
$$

The model under analysis with the relationships is shown in Figure 9

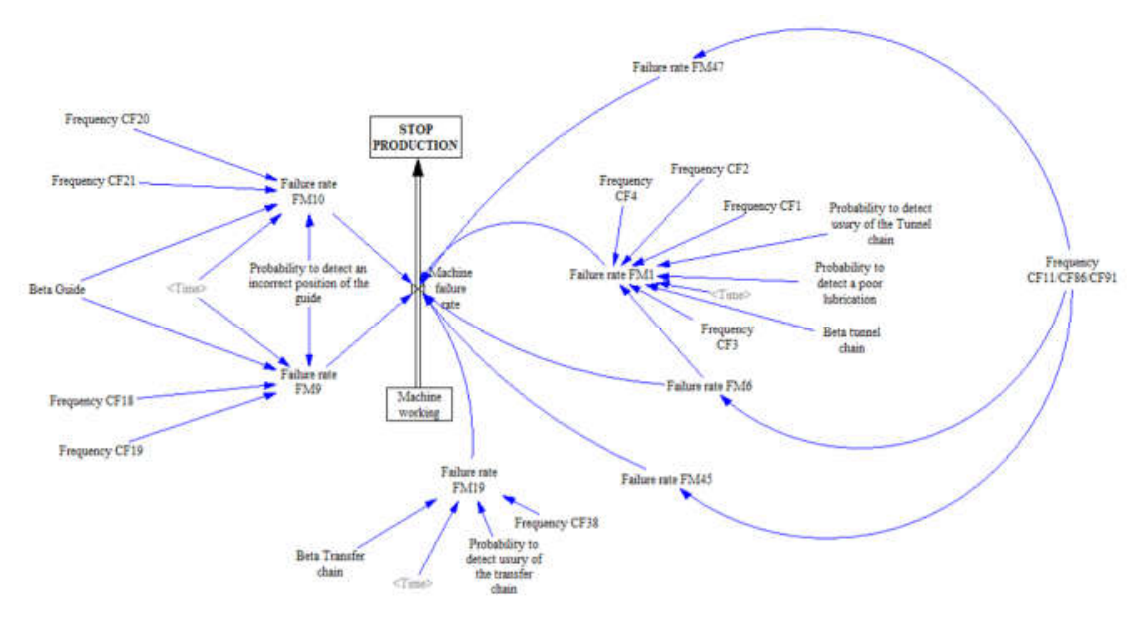

Figure 9. AS-IS model.

As shown in Figure 9, no maintenance variables have been inserted in the model, not because the maintenance activities have not been considered but because they have been incorporated within the failure rate functions of the various failure modes.

For the FM9 failure mode, misalignment of the guide an IF THEN ELSE cycle, with a cycle time of two quarters, has been set. This means that thanks to the adjustment operations carried out every two months, the conditions of the guide, seen from the point of view of alignment, are returned to the 0 state, as shown in Figure 10. 


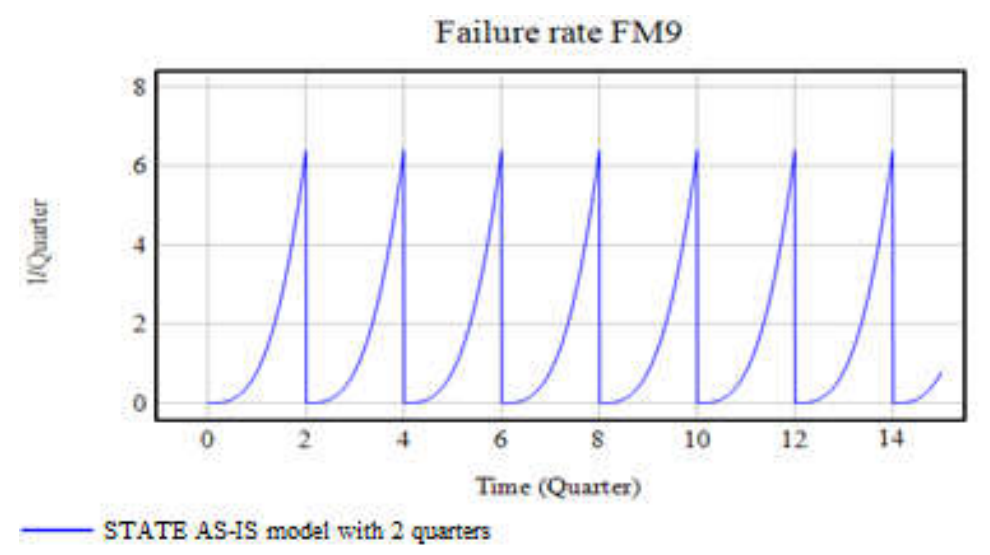

Figure 10. AS-IS FM9 Guide misalignment.

For the failure mode FM10, shown in Figure 11 on the other hand, a cycle time of 2 years has been set. This is because the guide is changed every two years, so its wear conditions are reset.

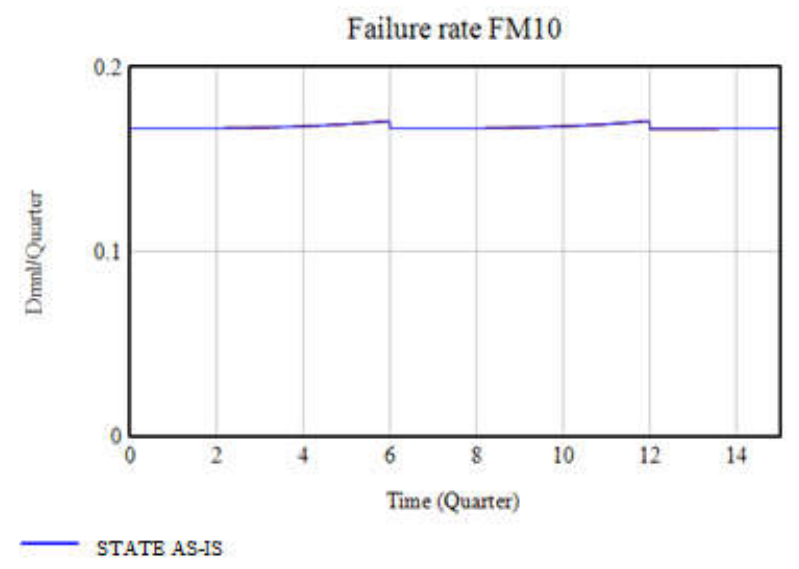

Figure 11. AS-IS FM10 Guide usury.

For the failure modes FM19 (transfer chain breakage) (Figure 10) and FM1 (tunnel chain breakage) (Figure 11), on the other hand, cycle times have been set as 3 and 4 years, respectively, because the two chains are changed with such intervals as required by the preventive maintenance plan drawn up manufacturer. 


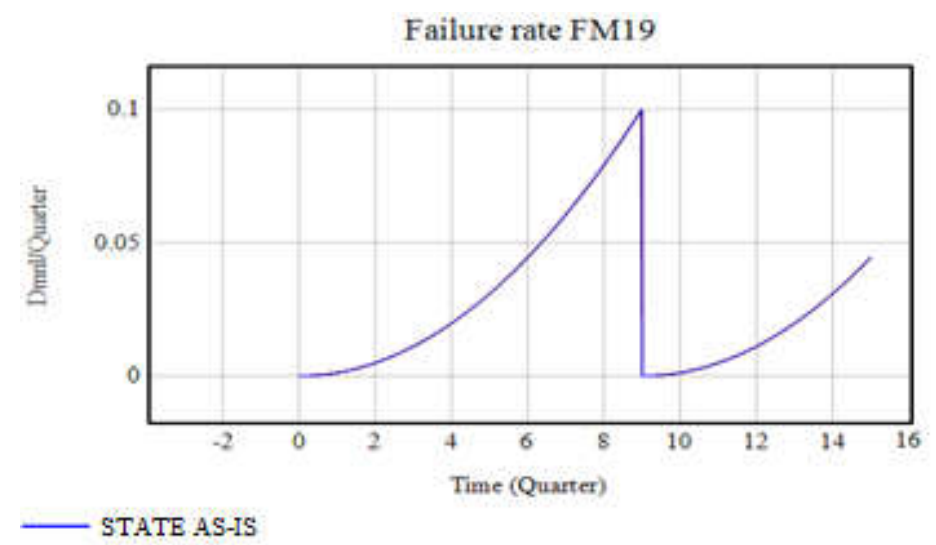

Figure 12. AS-IS FM19 Transfer chain breakdown.

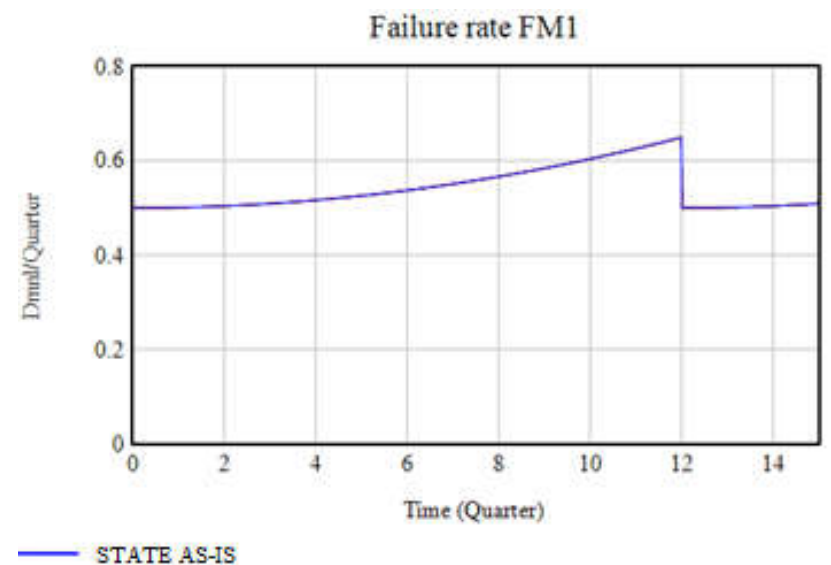

Figure 13. AS-IS FM1 Tunnel chain breakdown.

Once the trends of the various failure rates have been identified, all that remains is to identify that of the machine.

To do this, the total failure rate is obtained from the probability that all events can occur. The events can be considered as s-independent. The complete system status is presented in Figure 14.

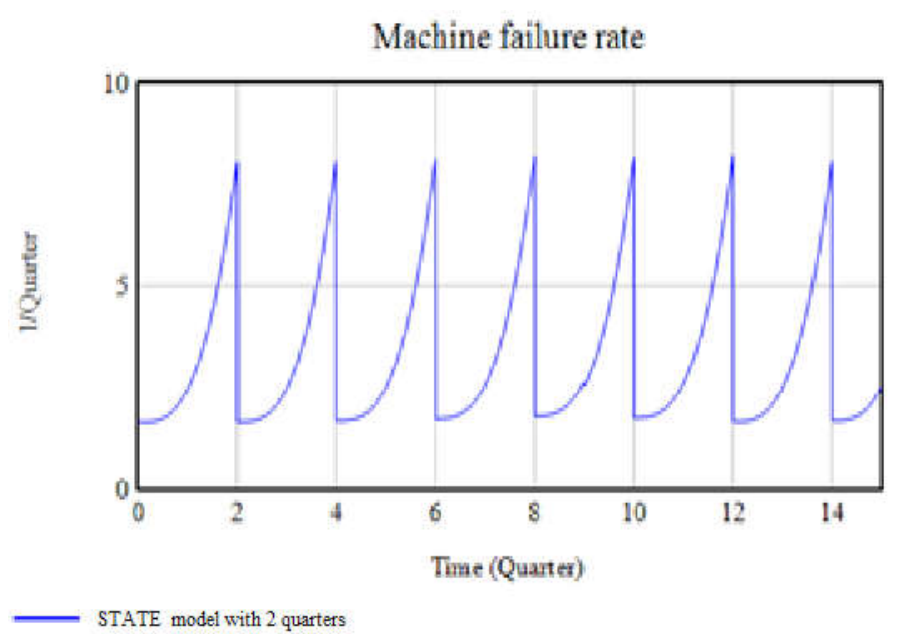

Figure 14. AS-IS failure rate diagram.

From the graph (Figure 14), it can be seen how the maintenance actions greatly influence the system's failure rate. 
Looking at all the graphs, you can also guess that the failure machine rate, the failure rate of the entire machine, is greatly influenced by the failure rate of the FM9 guide misalignment. This is because it is the most frequent failure that occurs.

The simulation was just made regarding the AS-IS status of the system, therefore considering the maintenance policies adopted in the company.

In the following, some corrective actions and their possible results are presented.

\subsection{Definition and impact assessment of corrective actions}

As seen, our machine's critical events concern the tunnel chain, the transfer chain, and the release guide.

Through simulation, that the component that has the greatest impact on the trend of the machine failure rate is the chicken release guide has been identified.

This component performs a fundamental task and must always be aligned in the right position. Unlike the chicken hooking guide, which plays a similar role, its task is made more complicated by the fact that the chickens arrive from the cooling tunnel where they have stayed at least 3 hours. This period causes the chicken to fasten to the hook of the tunnel chain, arriving at the chicken release area, the guide must undergo strong stress to be able to detach the chicken from the hook and must always be aligned correctly; otherwise, it runs the risk of spoiling or dropping the chicken.

To avoid fewer failures lower the chicken guide failure rate, you might think about increasing the guide adjustment frequency. This first action allows us to lower the probability of the failure occurring drastically.

Therefore, an $87.5 \%$ improvement in the guide failure rate is obtained with this first corrective action.

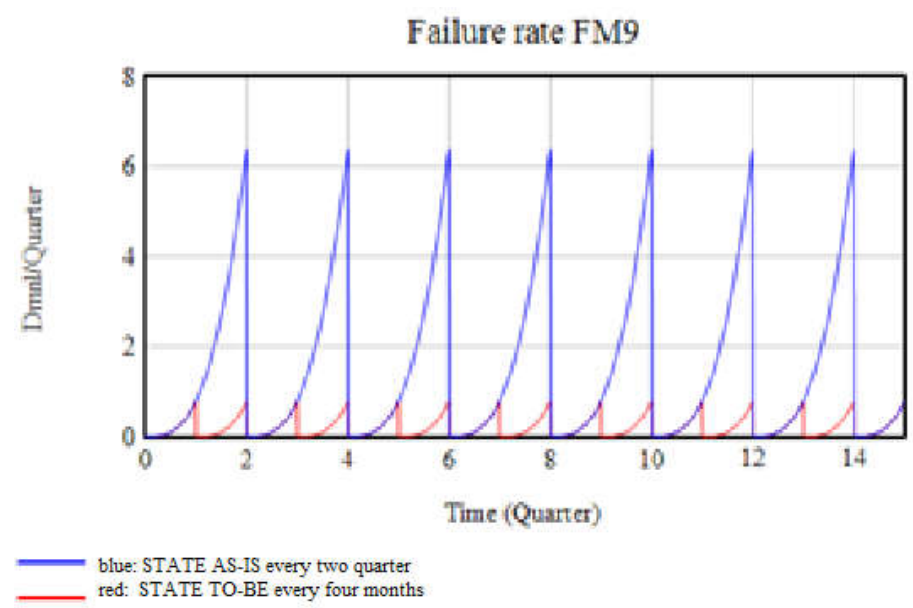

Figure 15, the FM9 failure rate with maintenance every four months. AS-IS state: guide adjustment rate every two quarters. TO-BE state: guide adjustment rate every four months.

Table 3. FM9 Failure rate.

\begin{tabular}{cccccccccc}
\hline Time (Quarter) & $\mathbf{0}$ & $\mathbf{0 . 5}$ & $\mathbf{1}$ & $\mathbf{1 . 5}$ & $\mathbf{2}$ & $\mathbf{2 . 5}$ & $\mathbf{3}$ & $\mathbf{3 . 5}$ & $\mathbf{4}$ \\
\hline $\begin{array}{c}\text { Failure rate FM9: STATUS TO-BE every four } \\
\text { months }\end{array}$ & 0 & 0.1 & 0.8 & 0.1 & 0.8 & 0.1 & 0.8 & 0.1 & 0.8 \\
\hline Failure rate FM9: STATUS AS-IS every two quarters & 0 & 0.1 & 0.8 & 2.7 & 6.4 & 0.1 & 0.8 & 2.7 & 6.4 \\
\hline
\end{tabular}

Therefore, to see how the situation changes in the case of the failure rate of the entire system, a significant improvement is also noted here as can be seen in Table 4 and Figure 16 precisely from a maximum of 8.23 to a maximum of 2.65 , with an improvement of $67.8 \%$ 


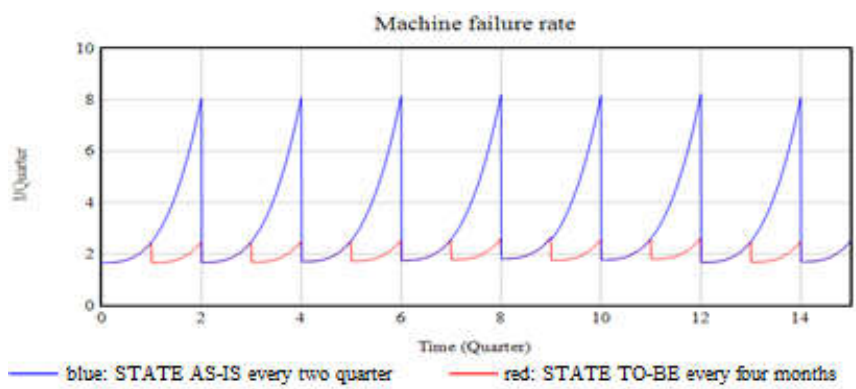

Figure 16. AS-IS / TO-BE machine failure comparison.

Other actions that can be implemented to lower the entire system's failure rate are to try to increase the detectability of some failure modes before they occur. In particular, two scenarios can be evaluated to reduce the failure rate of the chains:

The first scenario concerns the breakage of the electrical parts due to the blackout. Obviously, nothing can be done about it because it depends on external causes. The only actions that could be implemented to eliminate those failure modes are to install some emergency generators. However, this is a very expensive action that is not worth the risk due to the very low frequency of blackouts.

The second scenario analyses the failure rate of the chains due to their wear. It could be established either a greater number of checks by the maintenance technicians to identify signs of wear of the chains or establish automatic checks with sensors capable of identifying chain length variations.

The hypothesis is that it is possible to detect the fault of $90 \%$ thanks to one of these two choices.

In Figure 17 and Table 4, how the situation changes can be seen.

Table 4. AS-IS machine failure rate comparison.

\begin{tabular}{ccc}
\hline $\begin{array}{c}\text { Time (Quar- } \\
\text { ter) }\end{array}$ & $\begin{array}{c}\text { STATE TO-BE every four } \\
\text { months }\end{array}$ & STATE AS-IS every 2 quarters \\
\hline 0 & 1,67 & 1,67 \\
\hline 1 & 2,47 & 2,47 \\
\hline 2 & 2,48 & 8,08 \\
\hline 3 & 2,49 & 2,49 \\
\hline 4 & 2,50 & 8,10 \\
\hline 5 & 2,53 & 2,53 \\
\hline 6 & 2,55 & 8,15 \\
\hline 7 & 2,58 & 2,58 \\
\hline 8 & 0,26 & 0,82 \\
\hline 9 & 2,65 & 2,65 \\
\hline 10 & 0,26 & 0,82 \\
\hline 11 & 2,60 & 2,60 \\
\hline 12 & 2,63 & 8,23 \\
\hline 13 & 2,49 & 2,49 \\
\hline 14 & 0,25 & 0,81 \\
\hline 15 & 2,52 & 2,52 \\
\hline & & \\
\hline
\end{tabular}




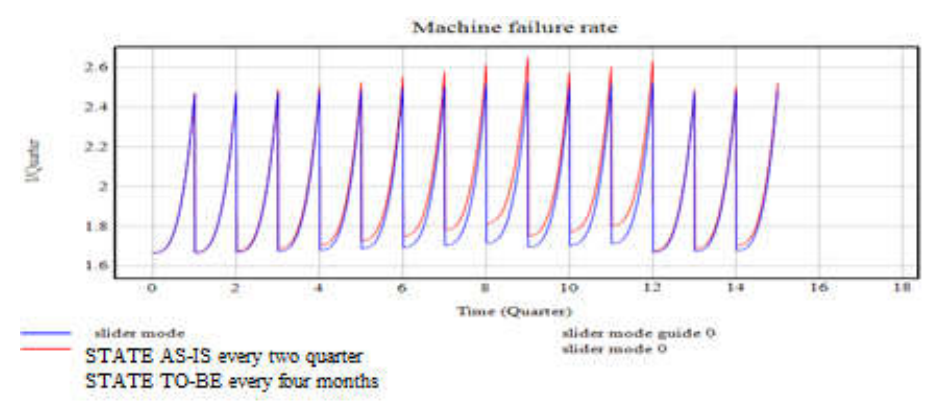

Figure 17. Machine Failure rate diagram.

The improvements are very little perceptible. There is a minimum improvement of about $5 \%$ from the frequency of the chains' breakings that is already minimal.

Indeed, it is advisable to increase the inspections by the maintenance technicians to be able to intervene promptly at every slightest deviation of the chain from the initial conditions to avoid accelerated wear. However, installing automatic detection systems such as sensors is not advisable because they are still expensive systems.

The first safe step on which to intervene is the chicken release guide.

A few corrective actions achieve great results in machine operation, thus limiting production stops to a minimum.

\section{Conclusion}

Companies' risk management is increasingly fundamental in manufacturing companies with an almost saturated production cycle.

It is fundamental to prevent the occurrence of a failure as much as possible because it leads, in most cases, to a loss of production and, therefore, to severe economic losses.

In the presented work, a development of the traditional FME is proposed where some innovative aspects have been added to eliminate some deficiencies present in the traditional FMEA/FMECA.

A fourth factor, the cost, has been added to consider the economic aspects and production aspects, absent in the traditional FMEA. Besides adding the cost factor, the four factors are weighted thanks to two MCDM: the objective Entropy method to derive the weights directly from the data structure and the BWM method to derive the weights of the factors from the subjective evaluations of the experts.

The use of simulation has allowed considering the dynamics aspects and the relationships between the various faults, which is impossible in a standard FMEA analysis where the causes are analysed individually and statically.

The analysis conducted shows how it can be possible to reduce the machine failure rate.

At this regard, a sensitivity analysis has been carried out to support the work carried out.

The future route can not ignore the presence of sensors and Industry 4.0 on the machineries. In this regard, new research will include the use of the application of Machine Learning to prevent faults and minimise the down time of the machine.

Conflicts of Interest: The authors declare no conflict of interest.

\section{References}

1. J. Bowles e C. Peláez, «Fuzzy logic prioritization of failures in a system failure mode, effects and criticality analysis,» Reliability Engineering and System Safety, vol. 50, pp. 203-213, 1995.DOI: https://doi.org/10.1016/0951-8320(95)00068-D

2. Braglia, M. (2020). MAFMA: Multi-attribute failure mode analysis. International Journal of Quality and Reliability Management, 1017-1033. DOI: https://doi.org/10.1108/02656710010353885

3. Braglia, M., Frosolini, M., \& Montanari, R. (2003). Fuzzy TOPSIS Approach for Failure Mode, Effects and Criticality Analysis. Quality and Reliability Engineering International, 425-443. DOI: https://doi.org/10.1002/qre.528 
4. C., G. K., DR, N., B., S., \& WS, R. (2018). impact of cloud-based information sharing on hospital supply chain performance: A system dynamics framework. International Journal of Production Economics, 195, 168-185. DOI: 10.1016/j.ijpe.2017.10.008

5. Carmignani, G. (2009). An integrated structural framework to cost-based FMECA: The priority-cost FMECA. Reliability Engineering \& System Safety, 94(4), 861-871. DOI: 10.1016/j.ress.2008.09.009

6. Chang, K.-H. (2009). Evaluate the orderings of risk for failure problems using a more general RPN methodology. Microelectronics Reliability, 49(12), 1586-1596. DOI: 10.1016/j.microrel.2009.07.057

7. Chin, K.-S., Wang, Y.-M., Poon, G. K., \& Yang, J.-B. (2009). Failure mode and effects analysis by data envelopment analysis. Decision Support Systems, 48(1), 246-256. DOI: https://doi.org/10.1016/j.dss.2009.08.005

8. Chin, K.-S., Wang, Y.-M., Poon, G. K., \& Yang, J.-B. (2009). Failure mode and effects analysis using a group-based evidential reasoning approach. Computers \& Operations Research, 36(6), 1768-1779. DOI: 10.1016/j.cor.2008.05.002

9. Ciani, L., Guidi, G., \& Patrizi, G. (2019). A Critical Comparison of Alternative Risk Priority Numbers in Failure Modes, Effects, and Criticality Analysis. DOI: 10.1109/ACCESS.2019.2928120

10. Cristea, G., \& Constantinescu, D. M. (2017). A comparative critical study between FMEA and FTA risk analysis methods. IOP Conference Series: Materials Science and Engineering, 252. DOI: 10.1088/1757-899X/252/1/012046

11. Ebeling, C. E. (2019). An introduction to reliability and maintainability engineering. Waveland press, inc.

12. Ekmekçioğlu, M., \& Kutlu, A. C. (2012). A fuzzy hybrid approach for fuzzy process FMEA: An application to a spindle manufacturing process. International Journal of Computational Intelligence Systems, 5(4), 611-626. DOI: 10.1080/18756891.2012.718104

13. H. Selim, M. Yunusoglu e Ş. Y. Balaman, «A dynamic maintenance planning framework based on fuzzy TOPSIS and FMEA: Application in an International Food Company, » Quality and Reliability Engineering International, vol. 32, n. 3, pp. 795-804, 2016. DOI: $10.1002 /$ qre.1791

14. Huang, J., You, J.-X., Liu, H.-C., \& Song, M.-S. (2020). Failure mode and effect analysis improvement: A systematic literature review and future research agenda. Reliability Engineering and System Safety, 199. DOI: 10.1016/j.ress.2020.106885

15. Kim, K., \& Zuo, M. (2018). General model for the risk priority number in failure mode and effects analysis. Reliability Engineering and System Safety, 169, 321-329. DOI: 10.1016/j.ress.2017.09.010

16. Kolios, A. Umofia e M. Shafiee, «Failure mode and effects analysis using a fuzzy-TOPSIS method: A case study of subsea control module» International Journal of Multicriteria Decision Making, vol. 7, n. 1, pp. 29-53, 2017. DOI: 10.1504/IJMCDM.2017.085154

17. Lipol, L. S., \& Haq, J. (2011). Risk analysis method: FMEA/FMECA in the organisations. International Journal of Basic \& Applied Sciences, 11(5).

18. Liu, H.-C., Chen, X.-Q., Duan, C.-Y., \& Wang, Y.-M. (2019). Failure mode and effect analysis using multi-criteria decision-making methods: A systematic literature review. Computers and Industrial Engineering, 135, 881-897. DOI: 10.1016/j.cie.2019.06.055

19. Liu, H.-C., Liu, L., \& Liu, N. (2013). Risk evaluation approaches in failure mode and effects analysis: A literature review. Expert Systems with Applications, 40, 828-838. DOI: 10.1016/j.eswa.2012.08.010

20. Liu, H.-C., Liu, L., Bian, Q.-H., Lin, Q.-L., Dong, N., \& Xu, P.-C. (2011). Failure mode and effects analysis using fuzzy evidential reasoning approach and grey theory. Expert Systems with Applications, 38(4), 4403-4415. DOI: 10.1016/j.eswa.2010.09.110

21. Liu H., L. Liu, N. Liu e L. Mao, «Risk evaluation in failure mode and effects analysis with extended VIKOR method under fuzzy environment, » Expert Systems with Applications, vol. 39, n. 17, pp. 12926-12934, 2012. DOI: 10.1016/j.eswa.2012.05.031

22. Lo, H., \& Liou, J. (2018). A novel multiple-criteria decision-making-based FMEA model for risk assessment. Applied Soft Computing, 73, 684-696. DOI: 10.1016/j.asoc.2018.09.020

23. Lo, H.-W. L. (December 2018). A novel multiple-criteria decision-making-based FMEA model for risk assessment. Applied Soft Computing Journal, 684-696. DOI: 10.1016/j.asoc.2018.09.020

24. Lolli, A. Ishizaka, R. Gamberini, B. Rimini e M. Messori, «FlowSort-GDSS - A novel group multi-criteria decision support system for sorting problems with application to FMEA» Expert Systems with Applications, 42 (17-18) (2015), pp. 6342-6349, vol. 42, n. 17-18, pp. 6342-6349, 2015. DOI: 10.1016/j.eswa.2015.04.028

25. Ouyang L., Zhu Y., Zheng W., Yan L. (2021) An information fusion FMEA method to assess the risk of healthcare waste. Journal of Management Science and Engineering. DOI: 10.1016/j.jmse.2021.01.001

26. Pillay, A., \& Wang, J. (2003). Modified failure mode and effects analysis using approximate reasoning. Reliability Engineering and System Safety, 79, 69-85. DOI: 10.1016/S0951-8320(02)00179-5

27. Seyed-Hosseini, S., Safaei, N., \& Asgharpour, M. (2006). Reprioritization of failures in a system failure mode and effects analysis by decision making trial and evaluation laboratory technique. Reliability Engineering and System Safety, 91(8), 872-881. DOI: 10.1016/j.ress.2005.09.005

28. Stamatis, D. (2003). Failure mode and effect analysis: FMEA from theory to execution. New York: ASQ Quality Press.

29. Tian, J. Wang e H. Zhang, «An integrated approach for failure mode and effects analysis based on fuzzy best-worst, relative entropy, and VIKOR methods» Applied Soft Computing Journal, vol. 72, pp. 636-646, 2018. DOI: 10.1016/j.asoc.2018.03.037

30. Trinkūnienè, E., Podvezko, V., \& Zavadskas, E. (2017). Evaluation of quality assurance in contractor contracts by multi-attribute decision-making. Economic Research-Ekonomska Istraživanja. DOI: 10.1080/1331677X.2017.1325616

31. Vala, S., Chemweno, P., Pintelon, L., \& Muchiri, P. (2018). A risk-based maintenance approach for critical care medical devices: a case study application for. International Journal of System Assurance Engineering and Management, 9, 1217-1233. DOI: 10.1007/s13198-018-0705-1 
32. Wang, P., Meng, P., Zhai, J.-Y., \& Zhu, Z.-Q. (2013). A hybrid method using experiment design and grey relational analysis for multiple criteria. Knowledge-Based Systems, 53, 100-107. DOI: 10.1016/j.knosys.2013.08.025

33. Wang, Y.-M., Chin, K.-S., Poon, G. K., \& Yang, J.-B. (2009). Risk evaluation in failure mode and effects analysis using fuzzy weighted geometric mean. Expert Systems with Applications, 36(2), 1195-1207. DOI: 10.1016/j.eswa.2007.11.028

34. Xu, K., Tang, L., Xie, M., Ho, S., \& Zhu, M. (2002). Fuzzy assessment of FMEA for engine systems. Reliability Engineering and System Safety, 75(1), 17-29. DOI: 10.1016/S0951-8320(01)00101-6 